\title{
Energy and nutrient intakes in a sample of 136 Edinburgh 7-8 year olds: a comparison with United Kingdom dietary reference values
}

\author{
BY C. H. S. RUXTON* AND T.R. KIRK† \\ Department of Nutrition and Dietetics, Queen Margaret College, Edinburgh, EH12 8TS \\ AND N. R. BELTON \\ Department of Child Life and Health, University of Edinburgh, Edinburgh
}

(Received 20 June 1994 - Revised 19 April 1995 - Accepted 12 May 1995)

\begin{abstract}
Energy and nutrient intakes were assessed in 136 children, aged 7-8 years and living in and around Edinburgh, using the $7 \mathrm{~d}$ weighed inventory technique. The results were compared with UK dietary reference values (DRV) for energy, macronutrients and micronutrients. NSP intakes were compared with a calculated reference value (CRV). Mean energy intakes were close to the estimated average requirement for both boys and girls. Mean percentages of food energy derived from fat and saturated fat were high in relation to DRV (37 and 14 compared with 35 and 11 respectively). Mean percentage of food energy derived from total carbohydrate was close to the DRV of 50 but intakes of starch appeared to be low and intakes of total sugars high ( 23 and $26 \%$ food energy respectively). Superficially, this suggests that there is a need to alter the balance of carbohydrate in favour of increasing starch and lowering total sugar. There was, however, a clear 'fat-sugar seesaw', i.e. children with a high percentage energy from total sugars had a low percentage energy from fat, and vice versa. In view of this finding, it is possible that efforts to reduce total sugar intake in children may result in a further increase in percentage energy from fat. Mean intakes of NSP were only $50 \%$ of the CRV, but this guideline may be set too high. Mean intakes of most micronutrients were above reference nutrient intakes. Reported low intakes of $\mathrm{Zn}$ and Se were treated with caution due to the perceived incompleteness of the data for these in the nutrient database. The authors concluded that targeting high intakes of total fat and saturated fat should be the health priorities in this age-group.
\end{abstract}

Dietary intake: Schoolchildren

'Clearly, Scotland's eating habits are established inappropriately from birth onwards and a dramatic change in public health strategy is needed' (Scottish Office, 1993)

The Scottish Office (1993), in a recent report on Scotland's health, has observed that 'The usual Scottish diet consumed by children is also that which we would now expect to be conducive to the development of adult chronic diseases'. However, in order to identify priorities for health promotion, recent data on a range of different age-groups is required. Notable dietary studies on children carried out over the last 10 years include those by Hackett et al. (1986), Benton \& Roberts (1988), Department of Health (1989), Nelson et al. (1990), McNeill et al. (1991), Payne \& Belton (1992) and Adamson et al. (1992). A description of the subjects and methods used in these studies is given in Table 1. However, only the studies of McNeill et al. (1991), Payne \& Belton (1992) and Department of Health (1989) included data on Scottish children. Most of these dietary surveys appear to

\footnotetext{
* Present address: 16 Inglewood Road, London NW6 1QZ.

$\dagger$ For reprints.
} 
Table 1. Dietary surveys on children published between 1984 and 1994

\begin{tabular}{llcrl}
\hline \hline Source & Location & $\begin{array}{c}\text { Age-range } \\
\text { (years) }\end{array}$ & Sample size & Methods \\
\hline Hackett et al. (1986) & Newcastle & $11-12$ & 405 & 3 d estimated inventory \\
Benton \& Roberts (1988) & London & $12-13$ & 90 & 3 d estimated inventory \\
Department of Health (1989) & Nationwide & $11-12,14-15$ & 2697 & 7 d weighed inventory \\
Nelson et al. (1990) & London & $7-12$ & 227 & 7 d weighed inventory \\
McNeill et al. (1991) & Dundee & 12 & 61 & 7 d weighed inventory \\
Payne \& Belton (1992) & Edinburgh & $2-5$ & 153 & 7d weighed inventory \\
Adamson et al. (1992) & Newcastle & $11-12$ & 379 & 3 d estimated inventory \\
\hline
\end{tabular}

concentrate on adolescents, leaving a 'gap' between the ages of 5 and 9 years. Apart from data on forty-nine 7-10 years old from the Nelson $e t$ al. (1990) study (the number of 7-8 year olds is not specified), to the authors' knowledge there has not been a focused dietary survey on this age-group since the work of Cook et al. (1973). Therefore, it is the aim of the present paper to present data on 7-8 year olds, relating energy and nutrient intakes to UK dietary reference values (DRV; Department of Health, 1991). This exercise includes a comparison with DRV for carbohydrate and fat. Although it is acknowledged that these DRV were aimed primarily at the adult population, the authors contend that their use in childhood may be justified given the probability that eating habits are formed during this time and that nutrition-related adult diseases may have their origins in childhood.

\section{SUBJECTS AND METHODS}

Ethical approval for the study was given in June 1989 by the Research Evaluation Committee of Lothian Region's Education Department. Five primary schools in the Edinburgh and South Queensferry area were selected at random by the Research Evaluation Committee, three of which were in areas with a mixed social class population, while two schools were in an area of multi-deprivation. Schools were contacted in October 1990 and data collection took place between February 1991 and March 1992 (excluding school holidays).

All children attending Primary 3 (i.e. those aged 7-8 years) in the selected schools formed the target population. The criteria for selection excluded any children suffering from chronic conditions which might affect dietary intakes, but this subsequently amounted to zero. Children from ethnic groups other than Caucasian were also excluded $(n 1)$, since it was believed that the traditional foods eaten by these children would not be represented adequately in the nutrient database. This resulted in a target population of 269 children. After a list of names was obtained from school records, a personalized letter was sent to each family outlining the aims of the study and asking for support. In total, 157 affirmative replies were received and these families were followed up with a visit to explain the study further. Subsequently 146 agreed to participate and, of these, seven failed to complete the study period. One subject's diary was discarded due to the child becoming ill during the study and the mother refusing to repeat the days during which little food was eaten, while the diaries of two subjects were discarded due to a poor standard of record keeping (identified because drinks were consistently omitted and items were recorded with highly unlikely weights). Thus, 133 diaries which contained seven complete days (including two weekend days) and three diaries which contained six complete days (including one weekend day) were finally accepted. 
The $7 \mathrm{~d}$ weighed inventory was used to estimate usual dietary intake. Following training (by C.H.S.R.), parents weighed and recorded all food and drink consumed by the children using Salter electronic scales weighing up to $2 \mathrm{~kg}$ in $2 \mathrm{~g}$ intervals. Leftovers were also measured in this way. During the study period, three visits were made to each participating family to provide encouragement, complete a questionnaire to ascertain social class and check the accuracy and completeness of dietary diaries. This latter task was done by assessing whether or not food weights were reasonable, checking for incomplete food descriptions and questioning the parents about possible omissions. School meals and leftovers were weighed by a trained research assistant each lunchtime, while snacks eaten by the children outside the home or school were recorded in a notebook, either by the responsible adult or by the child himself/herself.

Height was measured to $10 \mathrm{~mm}$ using a Minimetre portable stadiometer (Child Growth Foundation, London), while weight was measured to $0.5 \mathrm{~kg}$ using Soehne floor scales. Height and weight were expressed as standard deviation scores of 1990 British population standards (Freeman et al. 1995) after correcting for skewness in the weight standards using the LMS method (Cole, 1990).

Data were analysed using COMP-EAT 4.0 (Nutrition Systems Ltd, London) which uses the Royal Society of Chemistry database. The program was adapted to include 174 new foods; 150 used in a previous study by Payne (1991) and twenty-four added by the author. Composition data on the twenty-four new foods, mainly sweets and drinks, were obtained from manufacturers who were contacted by letter. Statistical analyses were carried out using SPSS for Windows (Statistical Package for Social Sciences, 1993) and Student's $t$ test was used to investigate differences between subgroups, a probability level of $P<0.05$ being accepted as significant. The Mann Whitney $U$ test was used where nutrient intakes did not follow a normal distribution (ascertained using the Kurtosis test). Pearson's correlation coefficient was used to investigate relationships between nutrients.

\section{RESULTS}

The final sample of 136 was made up of seventy-one girls and sixty-five boys. The socialclass distribution of the sample was close to that described by the Registrar General classification for Caucasians in Edinburgh (Office of Population Censuses and Surveys, 1990). Sixty-four children ( $47 \%$ ) came from non-manual families (social classes I-IIIa), while sixty-four ( $47 \%$ ) came from manual families (social classes III b-IV). Eight children $(6 \%)$ could not be classified in this manner as their mothers, who were single parents, did not have either a present or a previous occupation.

Mean heights and weights were close to the fiftieth percentile (Child Growth Foundation, London). Mean height in boys was $1.251 \mathrm{~m}$ and $1.245 \mathrm{~m}$ in girls. Mean weight was $25.3 \mathrm{~kg}$ for boys and $24.7 \mathrm{~kg}$ for girls. Mean BMI for both boys and girls were in excess of standards for children of this age-group (Rolland-Cachera et al. 1991) at 16.2 and 15.9 respectively.

It was believed that the energy intake results obtained from the $7 \mathrm{~d}$ weighed inventory method were suitably representative of the sample, since reported energy intakes were close to predicted energy intakes (PEI) calculated according to the equation of Livingstone $e t$ al. (1991) which was based on estimates of predicted energy expenditure. Mean energy intake in boys was $7.78 \mathrm{MJ}(106 \% \mathrm{PEI})$, while mean energy intake in girls was $7 \cdot 16 \mathrm{MJ}$ (108\% PEI).

Table 2 presents mean energy and nutrient intakes for boys and girls. Boys' diets were higher in energy $(P<, 0.005)$, protein $(P<0.05)$, fat $(P<0.05)$, carbohydrate $(P<0.001)$, starch $(P<0.005)$, resistant starch $(P<0.05)$, dietary fibre $(P<0.05)$, nicotinic acid equivalent $(P<0.05), \mathrm{Fe}(P<0.05)$ and $\mathrm{Zn}(P<0.05)$ than girls' diets. However, when 
Table 2. Mean daily energy and nutrient intakes of 7-8-year-old school boys and girls living in Edinburgh*

(Mean values and standard deviations)

\begin{tabular}{|c|c|c|c|c|c|c|}
\hline & \multicolumn{3}{|c|}{ Boys } & \multicolumn{3}{|c|}{ Girls } \\
\hline & Mean & SD & $\%$ DRV & Mean & SD & $\%$ DRV \\
\hline \multicolumn{7}{|l|}{ Percentage energy from: } \\
\hline Fat & $37 \cdot 4$ & $3 \cdot 72$ & - & 37.8 & $4 \cdot 22$ & - \\
\hline SFA & $13 \cdot 7$ & $2 \cdot 15$ & - & $14 \cdot 2$ & 2.23 & - \\
\hline MUFA & $11 \cdot 1$ & 1.82 & - & $11 \cdot 4$ & 1.91 & - \\
\hline PUFA & $5 \cdot 1$ & $1 \cdot 35$ & - & $5 \cdot 5$ & 1.53 & - \\
\hline Protein & $11 \cdot 8$ & 1.89 & - & 11.9 & 1.79 & - \\
\hline Carbohydrate & $50 \cdot 8$ & $4 \cdot 28$ & - & $50 \cdot 3$ & 4.82 & - \\
\hline Starch & $23 \cdot 1$ & $4 \cdot 51$ & - & $22 \cdot 6$ & $3 \cdot 33$ & - \\
\hline Sugars & $25 \cdot 5$ & $5 \cdot 72$ & - & $25 \cdot 9$ & $5 \cdot 21$ & - \\
\hline \multicolumn{7}{|l|}{ Energy: } \\
\hline MJ & 7.78 & 0.98 & $94 \cdot 4$ & $7 \cdot 16$ & 1.00 & $98 \cdot 3$ \\
\hline kcal & 1860 & 230 & - & 1700 & 234 & - \\
\hline Protein $(\mathrm{g})$ & $54 \cdot 2$ & $10 \cdot 8$ & 191 & 50.0 & $11 \cdot 1$ & 177 \\
\hline Fat $(\mathrm{g})$ & 77.5 & $13 \cdot 6$ & - & $72 \cdot 2$ & $13 \cdot 4$ & - \\
\hline Total SFA† $(\mathrm{g})$ & $28 \cdot 1$ & 5.59 & - & $26 \cdot 9$ & $5 \cdot 52$ & - \\
\hline Total MUFA† (g) & $23 \cdot 2$ & 5.02 & - & 21.8 & 5.09 & - \\
\hline Total PUFA $+(\mathrm{g})$ & $10 \cdot 5$ & $2 \cdot 98$ & - & $10 \cdot 4$ & $3 \cdot 11$ & - \\
\hline Carbohydrate (g) & 251 & 33.6 & - & 227 & $36 \cdot 4$ & - \\
\hline Total sugars $(\mathrm{g})$ & 126 & $30 \cdot 4$ & - & 118 & $30 \cdot 2$ & - \\
\hline Sucrose $(\mathrm{g})$ & $29 \cdot 3$ & $13 \cdot 0$ & - & 26.8 & $11 \cdot 8$ & - \\
\hline Starch (g) & 113 & $25 \cdot 4$ & - & 101 & $18 \cdot 8$ & - \\
\hline NSP $(g)$ & $8 \cdot 15$ & $2 \cdot 90$ & $54 \cdot 8$ & 7.95 & $2 \cdot 24$ & 59 \\
\hline Vitamin A $(\mu \mathrm{g})$ & 504 & 288 & 101 & 556 & 268 & 111 \\
\hline$\beta$-carotene $(\mu \mathrm{g})$ & 345 & 481 & - & 537 & 709 & - \\
\hline Vitamin $\mathbf{B}_{1}(\mathrm{mg})$ & 1.05 & $0 \cdot 28$ & 151 & 1.04 & $0 \cdot 32$ & 149 \\
\hline Vitamin $B_{2}(\mathrm{mg})$ & 1.64 & 0.61 & 164 & $1 \cdot 51$ & 0.47 & 151 \\
\hline Vitamin $B_{6}$ (mg) & $1 \cdot 43$ & 0.47 & 143 & $1 \cdot 34$ & 0.36 & 134 \\
\hline Vitamin $B_{12}(\mu \mathrm{g})$ & $3 \cdot 47$ & $1 \cdot 42$ & 347 & 3.25 & $1 \cdot 12$ & 325 \\
\hline Nicotinic acid equivalent $(\mathrm{mg})$ & $24 \cdot 2$ & $5 \cdot 54$ & 202 & $22 \cdot 4$ & $4 \cdot 73$ & 187 \\
\hline Folate $(\mu \mathrm{g})$ & 173 & $59 \cdot 6$ & 116 & 167 & $45 \cdot 6$ & 111 \\
\hline Vitamin C (mg) & $55 \cdot 4$ & $31 \cdot 8$ & 184 & $60 \cdot 0$ & 43.6 & 200 \\
\hline Vitamin D $(\mu \mathrm{g})$ & 1.95 & 0.89 & - & $2 \cdot 16$ & 1.03 & - \\
\hline Vitamin E (mg) & 5.89 & $2 \cdot 57$ & - & 5.93 & 2.88 & - \\
\hline $\mathrm{Ca}(\mathrm{mg})$ & 819 & 216 & 149 & 800 & 273 & 145 \\
\hline $\mathrm{Fe}(\mathrm{mg})$ & $10 \cdot 0$ & $4 \cdot 30$ & 115 & $8 \cdot 53$ & 2.09 & 99 \\
\hline $\mathrm{Zn}(\mathrm{mg})$ & 6.46 & 1.80 & $92 \cdot 3$ & 5.90 & 1.44 & 84 \\
\hline $\operatorname{Se}(\mu \mathrm{g})$ & $27 \cdot 3$ & $13 \cdot 0$ & $91 \cdot 0$ & $24 \cdot 2$ & 8.00 & 81 \\
\hline
\end{tabular}

SFA, MUFA, PUFA, saturated, monounsaturated and polyunsaturated fatty acids respectively; DRV, dietary reference values (Department of Health, 1991).

* For details of subjects and procedures, see pp. 152-153.

$\uparrow$ The fatty acid data do not add up to the value for total fat since values for glycerol are not shown.

nutrient density was examined there were no significant differences between the composition of the diets, suggesting that the differences between boys and girls were merely a function of total food intake.

\section{Comparison with dietary reference values}

Energy and macronutrients. Mean energy intakes in the present study were expressed as a percentage of estimated average requirement (EAR; Department of Health,1991), while mean protein and micronutrient intakes were expressed as a percentage of reference 
Table 3. Percentage of 7-8-year-old school boys and girls living in Edinburgh whose micronutrient intakes were below and above dietary reference values (Department of Health, 1991)*

\begin{tabular}{|c|c|c|c|c|c|c|c|c|}
\hline & \multicolumn{2}{|c|}{$<$ LRNI } & \multicolumn{2}{|c|}{$\begin{array}{c}\geqslant \text { LRNI } \\
\text { and }<\text { EAR }\end{array}$} & \multicolumn{2}{|c|}{$\begin{array}{c}\geqslant \mathrm{EAR} \\
\text { and }<\mathrm{RNI}\end{array}$} & \multicolumn{2}{|c|}{$\geqslant \mathrm{RNI}$} \\
\hline & $n$ & $\%$ & $n$ & $\%$ & $n$ & $\%$ & $n$ & $\%$ \\
\hline \multicolumn{9}{|l|}{ Girls (n 71) } \\
\hline 'Expected' & 2 & $2 \cdot 5$ & 34 & $47 \cdot 5$ & 34 & $47 \cdot 5$ & 2 & $2 \cdot 5$ \\
\hline Vitamin A & 4 & $5 \cdot 6$ & 9 & $12 \cdot 7$ & 19 & $26 \cdot 8$ & 39 & $54 \cdot 9$ \\
\hline Vitamin $\mathbf{B}_{\mathbf{1}}$ & 0 & 0 & 1 & $1 \cdot 4$ & 3 & $4 \cdot 2$ & 67 & $94 \cdot 4$ \\
\hline Vitamin $\mathbf{B}_{2}$ & 0 & 0 & 3 & $4 \cdot 2$ & 8 & $11 \cdot 3$ & 60 & $84 \cdot 5$ \\
\hline Vitamin $\mathrm{B}_{6}$ & 0 & 0 & 1 & $1 \cdot 4$ & 6 & $8 \cdot 5$ & 64 & $90 \cdot 1$ \\
\hline Vitamin $B_{12}$ & 0 & 0 & 0 & 0 & 0 & 0 & 71 & 100 \\
\hline Nicotinic acid equivalent & 0 & 0 & 0 & 0 & 1 & $1 \cdot 4$ & 70 & $98 \cdot 6$ \\
\hline Folate & 0 & $1 \cdot 4$ & 5 & $7 \cdot 0$ & 23 & $32 \cdot 4$ & 42 & $59 \cdot 2$ \\
\hline Vitamin C & 0 & 0 & 2 & $2 \cdot 8$ & 11 & $15 \cdot 5$ & 58 & $81 \cdot 7$ \\
\hline $\mathrm{Ca}$ & 0 & 0 & 1 & $1 \cdot 4$ & 10 & $14 \cdot 1$ & 60 & $84 \cdot 5$ \\
\hline $\mathrm{Fe}$ & 0 & 0 & 8 & $11 \cdot 3$ & 38 & $53 \cdot 5$ & 25 & $35 \cdot 2$ \\
\hline $\mathrm{Se}$ & 10 & $14 \cdot 1$ & 45 & $63 \cdot 4$ & 16 & $22 \cdot 5$ & 0 & 0 \\
\hline $\mathrm{Zn}$ & 3 & $4 \cdot 2$ & 30 & $42 \cdot 3$ & 21 & $29 \cdot 6$ & 17 & $23 \cdot 9$ \\
\hline \multicolumn{9}{|l|}{ Boys ( $n$ 65) } \\
\hline 'Expected' & 2 & $2 \cdot 5$ & 31 & $47 \cdot 5$ & 31 & $47 \cdot 5$ & 2 & $2 \cdot 5$ \\
\hline Vitamin A & 3 & $4 \cdot 6$ & 14 & $21 \cdot 5$ & 25 & $38 \cdot 5$ & 23 & $34 \cdot 5$ \\
\hline Vitamin $B_{1}$ & 0 & 0 & 1 & $1 \cdot 5$ & 4 & $6 \cdot 2$ & 60 & $92 \cdot 3$ \\
\hline Vitamin $\mathbf{B}_{2}$ & 0 & 0 & 2 & $3 \cdot 1$ & 7 & $10 \cdot 8$ & 56 & $86 \cdot 2$ \\
\hline Vitamin $\mathbf{B}_{6}$ & 0 & 0 & 1 & $1 \cdot 5$ & 3 & $20 \cdot 0$ & 51 & $78 \cdot 5$ \\
\hline Vitamin $\mathrm{B}_{12}$ & 0 & 0 & 0 & 0 & 0 & 0 & 65 & 100 \\
\hline Nicotinic acid equivalent & 0 & 0 & 0 & 0 & 1 & 1.5 & 64 & $98 \cdot 5$ \\
\hline Folate & 1 & $1 \cdot 5$ & 9 & $13 \cdot 8$ & 17 & $26 \cdot 2$ & 38 & $58 \cdot 5$ \\
\hline Vitamin C & 0 & 0 & 5 & $7 \cdot 7$ & 12 & $18 \cdot \overline{5}$ & 48 & $73 \cdot 8$ \\
\hline $\mathrm{Ca}$ & 0 & 0 & 0 & 0 & 7 & $10 \cdot 8$ & 58 & $89 \cdot 2$ \\
\hline $\mathrm{Fe}$ & 0 & 0 & 11 & $16 \cdot 9$ & 15 & $23 \cdot 1$ & 39 & 60 \\
\hline $\mathrm{Se}$ & 10 & $15 \cdot 4$ & 32 & $49 \cdot 2$ & 23 & $35 \cdot 4$ & 0 & 0 \\
\hline $\mathrm{Zn}$ & 4 & $6 \cdot 2$ & 11 & $16 \cdot 9$ & 30 & $46 \cdot 2$ & 20 & $30 \cdot 8$ \\
\hline
\end{tabular}

* For details of subjects and procedures, see pp. 152-153.

nutrient intake (RNI; Department of Health, 1991). Intakes of fat and carbohydrate were compared directly with DRV. The results presented in Table 2 show that mean energy intake in boys was $94 \%$ of the EAR, while the mean energy intake in girls was $98 \%$ of the EAR. Mean protein intake was almost double the RNI in boys (192\%) and slightly lower than this in girls $(177 \%)$.

Percentage food energy from fat (37) was in excess of DRV (35) for both boys and girls, as was the mean percentage energy from saturated fat at 14 (DRV 11). Percentage energy from carbohydrate met the DRV of 50, however, percentage energy from starch appeared low at 23 , while percentage sugars appeared too high at 26 . It was not possible to calculate non-milk extrinsic sugars.

Mean NSP intakes were expressed as a percentage of the calculated reference value (CRV) of $8 \mathrm{~g} \mathrm{NSP} / 4.2 \mathrm{MJ}$ (The Caroline Walker Trust, 1991) since, at present, there is no DRV for NSP intake in children. Thus, the CRV for NSP (g) for this age, using EAR for energy intakes in the calculation, were 15.2 for boys and 13.5 for girls. Mean NSP intake was just over half the CRV at $55 \%$ in boys and $59 \%$ in girls. 


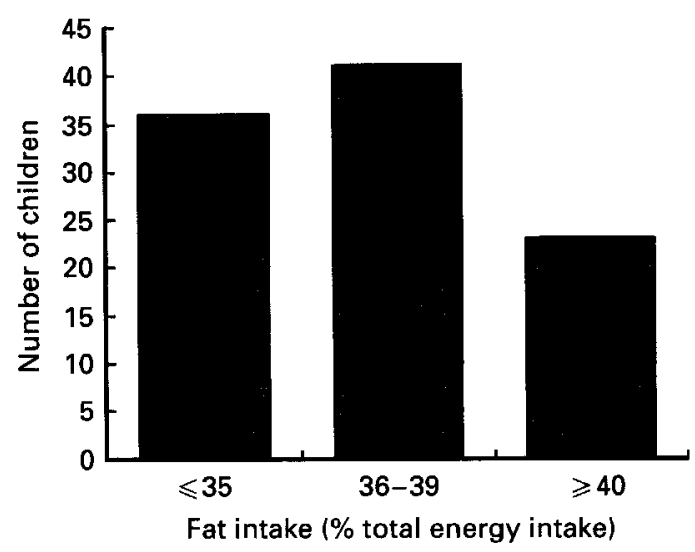

Fig. 1. Distribution of intakes for fat ( $\%$ total energy intake) of 7-8-year-old schoolchildren living in Edinburgh. For details of subjects and procedures, see pp. 152-153.

Micronutrients. Mean intakes of micronutrients were expressed as a percentage of the RNI. From Table 2 it can be seen that the majority of children in the present study had intakes in excess of the RNI for most nutrients, the exceptions being $\mathrm{Zn}$ and Se in the total sample and Fe in girls. However, group mean intakes can mask low intakes of individuals or subgroups. This was investigated by calculating the percentage of children with intakes below lower RNI (LRNI), above LRNI but below EAR, above EAR but below RNI and, finally, above RNI. Thus, if the distribution of nutrient intakes corresponds to the distribution of nutrient requirements indicated in the DRV report (Department of Health, 1991), the expected percentage of individuals falling into these groups would be $2 \cdot 5,47 \cdot 5$, 47.5 and 2.5 respectively. The actual distribution for both boys and girls is shown in Table 3 and clearly demonstrates that very few children had intakes less than the LRNI. Exceptions to this were the nutrients vitamin A, Se and $\mathrm{Zn}$, since more than the expected $2.5 \%$ of children fell below the LRNI.

\section{Relationship between percentages of energy derived from total fat and total sugar}

The DRV report (Department of Health, 1991) suggests that, in the adult diet, the population average for percentage food energy derived from carbohydrate and fat should be 50 and $35 \%$ of total energy respectively. We consider that it is appropriate to apply these DRV to the diets of school-age children. Mean intakes of carbohydrate and fat, expressed as percentage food energy, were 50 and 37 respectively which suggests that, while intakes of total carbohydrate were satisfactory, intakes of total fat were too high. This is shown further when the distribution of percentage energy from fat intakes is considered (Fig. 1). Although mean percentage energy from fat was 37 , eighty-seven $(64 \%)$ children had fat intakes in excess of $35 \%$ energy from fat, while thirty-one $(23 \%)$ children had intakes in excess of $40 \%$ energy from fat.

Mean intake of total sugars as a percentage of food energy also appeared high. Yet there is concern that the presence of an inverse relationship between percentage energies from total fat and total sugars could result in population fat intakes increasing if reductions in total sugar intakes are made. Such a relationship was investigated in the present paper using Pearson's correlation coefficient and Fig. 2 clearly illustrates that an inverse correlation is present $(r-0.65, P<0.001)$. There was also an inverse relationship between percentage energy from total sugars and percentage energy from saturated fat $(r-0 \cdot 24$; $P<0.01)$. 


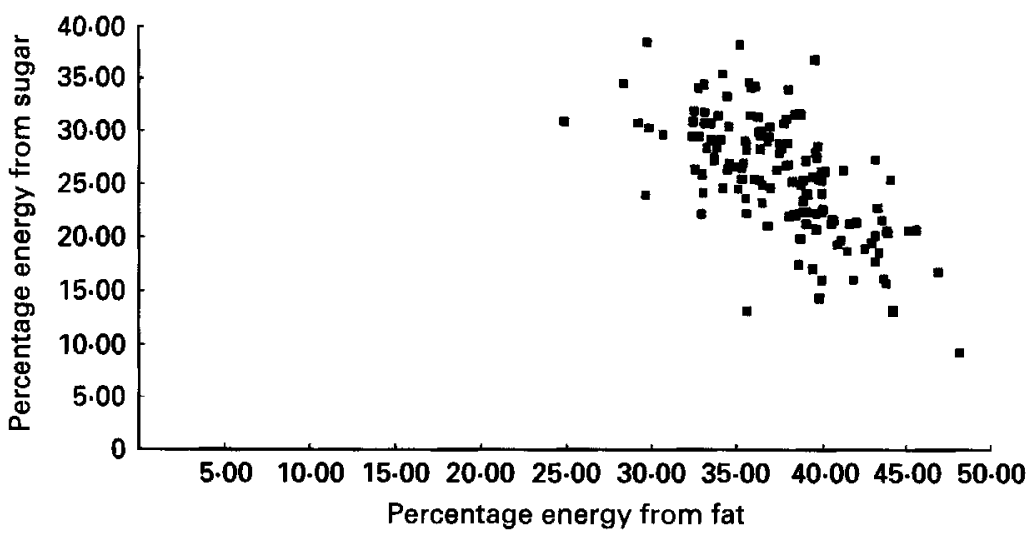

Fig. 2. Relationship between values for percentage food energy derived from total fat and that derived from sugar for 7-8-year-old schoolchildren living in Edinburgh. For details of subjects and procedures, see pp. 152-153 of proof.

Table 4. Five main sources of selected nutrients (not in order) and primary sources of selected nutrients (percentage of total sample) in a sample of 136 7-8-year-old schoolchildren living in Edinburgh*

\begin{tabular}{|c|c|c|c|c|c|c|c|c|c|}
\hline Total fat & & Total saturates & & Total sugars & & Starch & & NSP & \\
\hline \multicolumn{10}{|l|}{ Main source } \\
\hline Milk† & & Milk ${ }^{+}$ & & Milk $\dagger$ & & Bread $\|$ & & Potato crisps & \\
\hline Potato crisps & & Potato crisps & & Diluting juices & & Potato crisps & & Bread $\|$ & \\
\hline Margarine & & Cheese & & 'Fresh' juices§ & & RTEBC & & RTEBC & \\
\hline Processed meat & & Processed meat & & Chocolate & & Chips & & Chips & \\
\hline Cheese & & Chocolate & & 'Fizzy' drinks & & Potato & & Fruit & \\
\hline \multicolumn{10}{|c|}{ Primary source ( $\%$ of total sample) } \\
\hline Milk $\dagger$ & 37 & Milk $\dagger$ & 57 & Milk $\dagger$ & 26 & Bread $\|$ & 55 & Potato crisps & 43 \\
\hline Potato crisps & 33 & Cheese & 11 & 'Fresh' juices\$ & 23 & RTEBC & 25 & RTEBC & 27 \\
\hline Margarine & 11 & Potato crisps & 8 & Diluting juices & 18 & Potato crisps & 14 & Bread $\|$ & 20 \\
\hline Processed meat & 6 & Butter & 6 & 'Fizzy' drinks & 10 & Plain biscuits & 2 & Baked beans & 6 \\
\hline Cheese & 5 & Processed meat & 5 & Chocolate: & 6 & Processed meat & 2 & Potato & 2 \\
\hline Butter & 3 & Margarine & 5 & Table sugar & 5 & Rice & 2 & Pizza & 2 \\
\hline \multirow{3}{*}{\multicolumn{2}{|c|}{ Chocolate $\$$}} & Chocolate biscuits & 3 & Confectionery & 5 & & & & \\
\hline & & Plain biscuits & 2 & Sweet preserves & 3 & & & & \\
\hline & & Chocolate & 2 & $\begin{array}{l}\text { Fruit yoghurt } \\
\text { Chocolate biscuits }\end{array}$ & $\begin{array}{l}2 \\
2\end{array}$ & & & & \\
\hline
\end{tabular}

RTEBC, ready-to-eat breakfast cereal.

* For details of subjects and procedures, see pp. 152-153.

$\dagger$ Includes whole fat and semi-skimmed.

‡ Includes chocolate bars and chocolate-based confectionery.

$\$$ Includes those made from concentrates.

II Includes both wholemeal and white.

I Refers to other potatoes apart from chips and crisps.

Sources of fat, carbohydrate and non-starch polysaccharide

Attempts to alter nutritional intake in a population group must address specific food sources of target nutrients in order to be effective. Thus it was deemed important to investigate the major contributing foods to intakes of total fat, saturated fat, total sugars, starch and NSP in this sample of children. This was done in two ways: first by listing the 
main five sources of each nutrient for every child and combining the data to produce a table for the whole sample; and second by collating the primary source of each nutrient for every child and expressing this as a percentage of the total sample. The results are shown in Table 4 and reveal a number of interesting findings. Milk appeared to be the main source of total fat, saturated fat and total sugar, while potato crisps were an important source of total fat, saturated fat, starch and NSP. Fruit beverages and carbonated beverages contributed strongly to total sugar intakes. Bread and ready-to-eat breakfast cereals were important contributors to starch and NSP intakes.

\section{DISCUSSION AND CONCLUSIONS}

In interpreting the results of the present study, one should take into account that mean daily energy and nutrient intakes of children in the study were, in most cases, close to DRV (Department of Health, 1991), although it is accepted that the data reflect term-time dietary intakes. It would have been interesting and useful to collect data on intakes during the school holidays but this was not possible due to methodological constraints. Energy intakes in the present study were close to those of UK 7-10 year olds (Nelson et al. 1990) but lower than those of Swedish 7-8 year olds (Hagman et al. 1986) and higher than those of Australian 7-8 year olds (Magarey \& Boulton, 1987). Protein intakes were more than acceptable at $180 \%$ RNI, while mean percentage energy from protein (12) was close to that reported by other UK studies (Department of Health, 1989; Nelson et al. 1990; McNeill et al. 1991).

Reducing percentage energy from total fat and from saturated fat in adults and children over the age of 5 years is viewed by both Government and health workers as a key aim. Mean percentage energy from fat in this sample (37) exceeded the reference value (35) as did percentage energy from saturated fat $(14 v .11)$. The relatively high intakes of fat found in the present study are in accordance with results from other studies. Work conducted on UK children shows fat intakes of about $37 \%$ of energy for 5-8 year olds (Widdowson, 1947; Cook et al. 1973; Black et al. 1976) and about 38\% of energy for 11-12 year olds (Benton \& Roberts, 1988; Department of Health, 1989; McNeill et al. 1991). Non-UK studies on 7-8-year-old Caucasians report fat intakes of about $36 \%$ of energy (Australia: Magarey \& Boulton, 1987; Sweden: Hagman et al. 1986). The main source of fat and saturated fat in the present study was milk and it has been reported elsewhere that children drank significantly more full-fat milk than low-fat milk (Ruxton et al. 1996). Reductions in percentage energy from total fat and saturated fat could be made if 7-8-year-old children were encouraged to drink semi-skimmed milk and to consume less potato crisps, also an important contributor to fat intakes.

Mean carbohydrate intake as a percentage of food energy met the DRV of 50, but it was not possible to break down this value into non-milk extrinsic sugars and intrinsic plus milk sugars due to the limitations of the COMP-EAT 4.0 program. However, it was still apparent from the values for percentage energy from starch and from total sugar that the former was too low and the latter too high at 23 and 26 respectively. The estimation of mean sucrose intake was hindered by a lack of manufacturers' data on the sucrose content of confectionery, resulting in severe underestimation. Thus, the value of $28 \mathrm{~g}$ cannot be used as an approximation of non-milk extrinsic sugars. The main non-milk sources of sugars in the present study were juices and carbonated beverages and this has been found also by Payne (1991) in Edinburgh preschool children. A reduction in intake of sugars is desirable according to the DRV report (Department of Health, 1991) yet the 'fat-sugar seesaw' demonstrated in the present paper suggests that efforts to decrease percentage energy from total sugar may result in further increases in percentage energy from fat as it is unlikely that sugar will be replaced by starch. Based on strong evidence linking high 
intakes of total fat and saturated fat to coronary heart disease, the priority in the case of children should be a reduction in fat. Concerns that reductions in fat may adversely affect growth have not been justified in this sample of children (Ruxton et al. 1995).

Intakes of NSP were approximately $57 \%$ of the CRV advocated by The Caroline Walker Trust (1992). This guideline was used because there are no DRV for NSP intakes in children. It is difficult to make firm conclusions regarding the adequacy of the NSP intakes reported in the present study since there are few published data on actual NSP intakes in children and even less published evidence to suggest what constitutes a 'high' or 'low' NSP intake. Adamson et al. (1992) reported mean intakes of about $9 \mathrm{~g} \mathrm{NSP}$ for adolescents, which is only slightly more than the $8 \mathrm{~g}$ reported in the present study of 7-8 year olds. An additional point is that the CRV proposed by The Caroline Walker Trust (1992) is based simply on an attempt to 'scale-down' adult reference values on the basis of energy requirements. This may not be an appropriate method since children have higher energy requirements per $\mathrm{kg}$ body weight than adults. However, despite difficulty in establishing an 'ideal' NSP intake for children, it remains noteworthy that the primary source of NSP for $43 \%$ of children in the present study was potato crisps. Advocating replacing crisps with fruit as a snack may result in benefits to intakes of NSP as well as those of percentage energy from fat.

Research on adolescent children (Benton \& Roberts, 1988; Department of Health, 1989) has suggested that some UK children are at risk of low intakes of certain micronutrients, e.g. Fe, Ca, vitamin A, folate. This was not the case for the 7-8-year-old children in the present study. Mean intakes of most micronutrients were in excess of UK DRV and few children had intakes below LRNI. The distribution of data demonstrated that the majority of children had micronutrient intakes in excess of the RNI, suggesting that most micronutrient deficiencies were unlikely. Exceptions to this appeared to be vitamin $\mathrm{A}, \mathrm{Zn}$ and Se, since more than the expected $2.5 \%$ of children had intakes below LRNI. Certainly the low intakes of vitamin A found here agree with published work on Scottish children (Department of Health, 1989; McNeill et al. 1991; Payne \& Belton, 1992). However, the results for $\mathrm{Zn}$ and Se should be treated with caution since it is likely that they represent an underestimation of intake due to the incompleteness of the Royal Society of Chemistry database on which the COMP-EAT 4.0 program was based. Alternatively, the new DRV for these two nutrients may have been set too high. Further research on biochemical indices would be useful to establish whether or not clinical deficiencies in $\mathrm{Zn}$ and Se exist, particularly since DRV have been set for the first time. It is thought that high intakes of antioxidant nutrients (vitamins $\mathrm{C}$ and $\mathrm{E}, \beta$-carotene, $\mathrm{Zn}$ and $\mathrm{Se}$ ) may have a role to play in the prevention of chronic adult diseases. However, since there is inadequate information on what constitutes optimal levels of intake, the adequacy of intakes in the present study cannot be assessed. It is hoped, nevertheless, that the data presented on vitamin $E$ and $\beta$ carotene intakes in the present paper will benefit future researchers in this area.

The evidence from the present study only partially confirms the opening observation that 'The usual Scottish diet consumed by children is also that which we would now expect to be conducive to the development of adult chronic diseases' (Scottish Office, 1993). Clearly, there is a need to reduce percentage energy from total fat and from saturated fat in children as these are likely to contribute to later obesity, coronary heart disease and cancers. Intakes of NSP appear to be low, which could potentially contribute to later colonic disease, if sustained. However, conclusions cannot be drawn until satisfactory reference values for NSP in children have been established. Intakes of most micronutrients were satisfactory and the risk of deficiencies in this particular age-group would not appear to be an area of public health concern. Instead, the focus should be on reducing intakes of total fat and of saturated fat, possibly by targeting the main food sources of these in children's diets. 
The authors would like to thank the schools and families participating in the study and gratefully acknowledge the financial assistance given by the Kellogg Company of Great Britain Limited and the Scottish Dairy Council.

\section{REFERENCES}

Adamson, A., Rugg-Gunn, A., Butler, T., Appleton, D. \& Hackett, A. (1992). Nutritional intake, height and weight of 11-12-year-old Northumbrian children in 1990 compared with information obtained in 1980. British Journal of Nutrition 68, 543-563.

Benton, D. \& Roberts, G. (1988). Effect of vitamin and mineral supplementation on intelligence of a sample of schoolchildren. The Lancet i, 140-143.

Black, A. E., Billewicz, W. Z. \& Thomson, A. M. (1976). The diets of pre-school children in Newcastle upon Tyne, 1968-1971. British Journal of Nutrition 35, 105-113.

Cole, T. J. (1990). The LMS method for constructing normalised growth standards. European Journal of Clinical Nutrition 44, 45-60.

Cook, J., Altman, D. G., Moore, M. C., Topp, S. G., Holland, W. W. \& Elliott, A. (1973). A survey of the nutritional status of schoolchildren - relationship between nutrient intake and socio-economic factors. British Journal of Preventative and Social Medicine 27, 91-99.

Department of Health (1989). The Diets of British Schoolchildren. Report on Health and Social Subjects no. 36. London: H.M. Stationery Office.

Department of Health (1991). Dietary Reference Values for Food Energy and Nutrients for the United Kingdom. Report on Health and Social Subjects no. 41. London: H.M. Stationery Office.

Freeman, J. V., Cole, T. J., Chinn, S., Jones, P. R. M., White, E. M. \& Preece, M. A. (1995). Cross-sectional and weight reference curves for the UK, 1990. Archives of Disease in Childhood 73, 17-24.

Hackett, A. F., Rugg-Gunn, A. J., Appleton, D. R. \& Coombs, A. (1986). Dietary sources of energy, protein, fat and fibre in 375 English adolescents. Human Nutrition: Applied Nutrition 40A, 176-184.

Hagman, U., Bruce, A., Persson, L., Samuelson, G. \& Sjölin, S. (1986). Food habits and nutrient intake in childhood in relation to health and socio-economic conditions. A Swedish multicentre study 1980-81. Acta Paediatrica Scandinavica Suppl. 328.

Livingstone, M. B. E., Prentice, A. M., Coward, W. A., Strain, J. J., Black, A. E., Davies, P. S. W., Stewart, C. M., McKenna, P. G. \& Whitehead, R. G. (1992). Validation of estimates of energy intakes by weighed dietary record and diet history in children and adolescents. American Journal of Clinical Nutrition 56, 29-35.

McNeill, G., Davidson, L., Morrison, D. C., Crombie, I. K., Keighran, J. \& Todman, J. (1991). Nutrient intake in school children: some practical considerations. Proceedings of the Nutrition Society 50, 37-43.

Magarey, A. \& Boulton, T. J. C. (1987). Food intake during childhood: percentiles of food energy, macronutrient intake and selected micronutrients from infancy to eight years of age. Medical Journal of Australia 147, 124-127.

Nelson, M., Naismith, D. J., Burley, V., Gatenby, S. \& Geddes, N. (1990). Nutrient intakes, vitamin-mineral supplementation, and intelligence in British schoolchildren. British Journal of Nutrition 64, 13-22.

Office of Population Censuses and Surveys (1990). Registrar General Classification of Occupations. London: H.M. Stationery Office.

Payne, J. A. (1991). Nutrient intake and growth in pre-school children. PhD Thesis, University of Edinburgh.

Payne, J. A. \& Belton, N. R. (1992). Nutrient intake and growth in pre-school children. II. Intake of minerals and vitamins. Journal of Human Nutrition and Dietetics 5, 299-304.

Rolland-Cachera, M. F., Cole, T. J., Sempé, M., Tichet, J., Rossignol, C. \& Charraud, A. (1991). Body mass index variations: centiles from birth to 87 years. European Journal of Clinical Nutrition 45, 13-21.

Ruxton, C. H. S., Kirk, T. R. \& Belton, N. R. (1996). The contribution of specific dietary patterns to energy and nutrient intakes in 7-8-year-old Scottish schoolchildren. I. Milk drinking. Journal of Human Nutrition and Dietetics 9 (In the Press).

Ruxton, C. H. S., Kirk, T. R. \& Belton, N. R. (1995). No adverse effects on growth seen in Scottish school children consuming either low fat diets or diets relatively high in non-starch polysaccharide. Health Bulletin $\mathbf{5 3}$, 398-401.

Scottish Office (1993). Scotland's Health. A Challenge to Us All. Report of a Working Party to the Chief Medical Officer for Scotland. Edinburgh: H.M. Stationery Office.

Statistical Package for Social Sciences (1993). SPSS for Windows. Chicago, Ill.: SPSS Inc.

The Caroline Walker Trust (1992). Nutritional Guidelines for School Meals. London: The Caroline Walker Trust.

Widdowson, E. M. (1947). A Study of Individual Children's Diets. Medical Research Council Special Report Series no. 257. London: H.M. Stationery Office. 